\title{
Peran Penambahan DHA pada Susu Formula
}

\author{
Helena Anneke Tangkilisan*, Hesti Lestari* ${ }^{*}$
}

Pertumbuhan otak yang pesat dalam masa pacu tumbuh otak membutuhkan bahan 60\% lemak, diantaranya Docosahexaenoic acid (DHA) yang merupakan asam lemak tak jenuh ganda rantai panjang omega 3. Umumnya susu formula yang beredar saat ini tidak mengandung asam lemak tak jenuh ganda rantai panjang dengan atom karbon lebih dari 18. ASI bukan hanya mengandung asam oleat (18:2n-6) dan asam linolenat (18:3n-3) tapi juga mengandung asam arakidonat (20:4n-6) dan DHA (22:6n-3). Pada masa janin, DHA dan asam arakidonat didapatkan melalui transfer plasenta. Setelah lahir, diperoleh dari diet atau melalui sintesis pemanjangan rantai dan desaturasi dari asam linoleat dan linolenat. Bayi yang hanya minum susu formula sepenuhnya tergantung pada sintesis endogen dari asam lemak tak jenuh rantai panjang. Penelitian menunjukkan dalam korteks cerebri terdapat kadar DHA yang lebih tinggi pada bayi yang mendapat ASI dibandingkan dengan yang minum susu formula tanpa DHA. Terdapat perbedaan tumbuh kembang antara bayi yang mendapat ASI dan yang mendapat susu formula tanpa DHA. Penambahan DHA dalam komposisi dengan kadar seperti pada ASI telah direkomendasikan oleh banyak lembaga kesehatan.

Kata kunci: Pacu tumbuh otak - DHA-ASI - susu formula

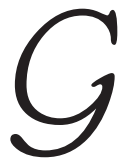

izi bagi bayi merupakan hal yang penting karena pada masa ini terdapat pertumbuhan pesat dari jaringan, termasuk pertumbuhan otak. Pertumbuhan otak yang pesat terbentuk disebut pacu tumbuh otak (brain growth spurt) terjadi sejak dalam kandungan dan dilanjutkan pada awal kehidupan. Diantara bahan yang dibutuhkan untuk pertumbuhan otak, kira-kira $60 \%$ adalah lemak. Lemak yang dibutuhkan untuk pembentukan struktur otak janin dan bayi dibentuk dari bahan lain seperti karbohidrat dan keton. Pengecualian adalah asam lemak esensial yang memerlukan asupan dari luar, lewat

*Kepala Subbagian Gizi Bagian Ilmu Kesehatan Anak FK Unsrat-RSUP Manado ( Dr. HA Tangkilisan, SpA. ) dan ** Peserta Program Pendidikan Dokter Spesialis Ilmu Kesehatan Anak FK Unsrat-RSUP Manado. (Dr. Hesti Lestari)

Alamat Korespondensi:

Dr. HA Tangkilisan, SpA.

Bagian Ilmu Kesehatan Anak FK Unsrat - RSUP Manado P.O Box 1066

- Manado.

Telepon: 0431-821652 Fax. 0431-859091. Email: ikarsup@telkom.net plasenta pada janin dan pada bayi melalui diet. ${ }^{1-4}$

Penelitian dalam bidang gizi bayi terutama komposisi asam lemak pada otak hingga saat ini masih terus berkembang. Salah satu zat gizi yang akhir-akhir ini menarik perhatian dalam bidang ini adalah docosahexaenoic acid (DHA) yang merupakan asam lemak tak jenuh ganda rantai panjang omega 3. Docosahexaenoic acid cukup banyak terdapat dalam air susu ibu, dan dalam banyak penelitian dihubungkan dengan pertumbuhan otak serta kemampuan kognitif, psikomotor maupun ketajaman penglihatan. ${ }^{5-11}$

Komposisi asam lemak dalam susu formula berbeda dengan ASI. Pada umumnya susu formula yang beredar saat ini tidak mengandung asam lemak tak jenuh ganda rantai panjang dengan jumlah atom karbon lebih dari 18 sebaliknya ASI bukan hanya mengandung asam oleat (18:2n-6) dan asam linolenat (18:3n-3) tapi juga asam arakidonat (20:4n-6) dan DHA (22:6n-3). ${ }^{11-13}$ Pada masa janin, DHA dan asam arakidonat didapatkan melalui transfer plasenta. Setelah lahir, bahan-bahan ini diperoleh dari diet ataupun melalui sintesis pemanjangan rantai dan 
desaturasi dari asam linoleat dan linolenat. Bayi yang hanya minum susu formula sepenuhnya tergantung pada sintesis endogen dari asam lemak tak jenuh rantai panjang. ${ }^{14}$ Penelitian menunjukkan dalam korteks cerebri terdapat kadar DHA yang lebih tinggi pada bayi yang mendapat ASI dibandingkan dengan yang minum susu formula. ${ }^{13,15,16} \mathrm{Hal}$ ini menimbulkan banyak dugaan dan diperlukan penelitian kembali mengenai perlunya penambahan DHA pada susu formula.

\section{Definisi}

Docosahexaenoic acid (DHA) merupakan suatu asam lemak tak jenuh ganda rantai panjang (Long-chain polyunsaturated fatty acid $=$ LC-PUFA). Struktur DHA adalah C22:6n-3, dengan 22 atom karbon dan memiliki 6 ikatan rangkap pada rantai asam lemak tersebut. Letak ikatan rangkap mulai pada atom karbon nomor 3 dari gugusan metil sehingga disebut sebagai omega $3(n-3) .{ }^{14,17}$

\section{Asam Lemak Esensial}

Asam lemak tak jenuh dapat dibedakan menurut letak ikatan rangkap pertama dari atom karbon gugusan metil, dan dikenal asam lemak omega 3 (n-3), omega 6 (n-6), omega 9 (n-9). ${ }^{17}$

Tubuh manusia dapat membuat asam lemak omega 9 dari asam lemak jenuh, karbohidrat atau keton sehingga asam lemak omega 9 disebut asam lemak tidak esensial. Sebaliknya, tubuh manusia tidak dapat membuat ikatan rangkap pada posisi n-3 dan n-6 sehingga asam lemak omega 3 dan omega 6 harus diperoleh dari sumber di luar tubuh, karena itu disebut sebagai asam lemak esensial. . $^{3,11,17}$

Fungsi terpenting dari asam lemak esensial adalah sebagai konstituen bermacam-macam fosfolipid yang penting sebagai lemak struktural dan fungsional dalam membran sel dan mitokondria, serta sebagai prekursor untuk biosintesis beraneka ragam senyawa eikosanoid seperti prostaglandin, tromboksan dan leukotrien. ${ }^{17-19}$ Asam linoleat, asam a-linolenat dan asam oleat termasuk dalam kelompok asam lemak tak jenuh. Dalam tubuh asam lemak tak jenuh dapat mengalami desaturasi dan pemanjangan rantai karbon serta membentuk asam lemak tak jenuh rantai panjang. ${ }^{3}$
Enzim yang dibutuhkan untuk terjadinya reaksi tersebut terdapat di hati, otak dan retina. Desaturasi dan pemanjangan rantai akan mengubah asam lemak tak jenuh seri n-9 menjadi asam mead. seri n- 6 akan diubah menjadi asam arakidonat sedangkan seri n-3 akan diubah menjadi DHA. ${ }^{3,17}$

\section{Sumber Alamiah DHA}

Dalam alam, jalur biokimia untuk membuat asam lemak tak jenuh ganda n-3 dan n-6 (asam linoleat dan asam a-linolenat) hanya terdapat pada kloroplast sel tumbuhan, algae dan beberapa jamur, sehingga tumbuhan merupakan sumber utama asam lemak esensial ini. Ikan dan beberapa binatang laut tertentu mendapatkan bahan ini dari fitoplankton dalam rantai makanannya. Selanjutnya tubuhnya mampu memproses lebih lanjut melalui kerja enzim elongase dan desaturase sehingga minyak ikan menjadi sumber yang kaya akan DHA khususnya ikan laut dalam seperti salmon, mackerel, herring dan tuna. Manusia juga mempunyai sistim enzim untuk memperpanjang rantai dan desaturasi, sehingga dapat membuat DHA dan asam arakidonat dari asam lemak n-3 dan n-6. ${ }^{20}$ Dengan demikian manusia dapat memperoleh DHA dari minyak ikan maupun dari prekursornya yang terdapat dalam minyak tumbuhan.

\section{Kandungan DHA pada Bayi Baru Lahir}

Selama kehamilan, asupan diet dan cadangan asam lemak n-3 pada ibu penting untuk menjamin jumlah asam lemak n-3 yang adekuat pada bayi saat lahir. Seluruh asam lemak tak jenuh ganda termasuk DHA dapat ditransfer melalui plasenta. Transfer ini berlangsung cepat saat trimester ketiga kehamilan, saat terjadi pacu tumbuh otak. Otak bayi membutuhkan sekitar 21 gram DHA tiap minggu selama trimester ini. ${ }^{3,21}$ Bayi prematur kehilangan kesempatan memperoleh cukup asam lemak n-3 pada trimester terakhir kehamilan, karena itu kandungan asam lemak tersebut pada bayi prematur lebih rendah dari pada bayi matur.

Setelah lahir, kebutuhan asam lemak n-3 pada bayi dapat difasilitasi oleh enzim desaturase dan elongase, namun pada bayi prematur, jumlah enzim tersebut masih rendah. Di lain pihak, aktifitas enzim desaturase dan elongase juga masih sangat kurang, sehingga bayi 
prematur kurang dapat mensintesa LC-PUFA seperti DHA dan asam arakidonat dari prekursornya. ${ }^{42,44-46}$

\section{Lemak dalam ASI}

Kadar asam lemak dalam ASI relatif sama dengan air susu mamalia lainnya, sekitar 4-8 gram persen dari air susu. Yang berbeda adalah komposisi/susunan asam lemaknya, yaitu ASI selain mengandung asam lemak dengan rantai 12 sampai 18 , juga mengandung asam lemak tak jenuh ganda rantai panjang seperti DHA dan asam arakidonat. ${ }^{22}$ Susu formula yang dipasarkan, hanya mengandung prekursornya, yaitu asam linoleat dan a-linolenat. ${ }^{23}$ Dengan demikian untuk memenuhi kebutuhan DHA dan asam arakidonat, bayi yang hanya mendapat susu formula saja harus mensintesis sendiri dengan menggunakan sistim enzim yang tersedia. ${ }^{11,22}$

Kadar DHA dalam ASI menurut Makrides dkk, berkisar $0,1-1 \%$ tergantung pada diet ibu. Haris $\mathrm{dkk}^{13}$ dalam penelitiannya tahun 1984 melaporkan bahwa kadar DHA dalam ASI dapat meningkat hingga 4,8\% jika ibu mengkonsumsi suplemen minyak ikan dengan kandungan DHA 47 gram tiap hari.

\section{Lemak dalam Susu Formula}

Lemak dalam susu formula telah mengalami banyak perkembangan sejak pertama kali diperkenalkan. Mulamula digunakan lemak yang berasal dari minyak kelapa atau minyak jagung yang banyak mengandung asam linoleat tapi sedikit asam a-linolenat. ${ }^{1}$ Saat itu tujuan penambahan lemak pada susu formula hanya sebagai sumber energi untuk menunjang pertumbuhan bayi. Banyak peneliti berasumsi bahwa komposisi lemak pada susu formula saat itu sudah dapat membuat bayi mencapai tingkat pertumbuhan yang sama dengan bayi yang minum ASI. Tetapi, akhir-akhir ini disadari bahwa pengukuran tingkat pertumbuhan saja tidak cukup dan harus dinilai juga perkembangan fisik dan mental. ${ }^{22}$

Di Amerika Serikat sejak tahun 1980-an mulai diperkenalkan formula yang mengandung lemak yang berasal dari kacang kedele; formula ini mengandung asam linoleat dan asam a-linolenat dengan ratio $7: 1$, suatu ratio yang lebih mendekati ASI. Selain itu penggunaan minyak kacang kedele meningkatkan konsentrasi asam lemak n-3 dalam formula yang beredar akhir-akhir ini. ${ }^{1}$
Perdebatan terjadi mengenai perlu tidaknya penambahan asam lemak tak jenuh ganda rantai panjang pada susu formula, sehingga susu formula semakin menyerupai ASI. Beberapa penelitian yang dilakukan akhir-akhir ini ditujukan untuk menilai peran penambahan DHA dan asam arakidonat pada susu formula.

\section{Perbedaan Kadar DHA pada Bayi dengan ASI dan Bayi dengan Susu Formula}

Clark dkk ${ }^{15}$ pada penelitian tahun 1992 membandingkan kadar DHA dan asam arakidonat pada bayi yang mendapat susu formula standar dan bayi yang mendapat ASI. Dilaporkan bahwa persentase DHA dan AA pada plasma dan eritrosit bayi yang mendapat susu formula lebih rendah dibandingkan dengan bayi yang mendapat ASI.

Pada penelitian postmortem yang dilakukan Farquharson dkk ${ }^{16}$ tahun 1992 dan Makrides dkk tahun 1994 didapatkan hasil bahwa otak bayi yang mendapat ASI memiliki persentase DHA yang lebih tinggi dari pada bayi yang mendapat susu formula. Hal ini menimbulkan dugaan bahwa sistim enzim desaturase dan elongase mungkin masih belum matang dan belum mampu mensintesa banyak DHA. Makrides juga menyimpulkan bahwa kadar DHA pada eritrosit dapat digunakan sebagai prediktor DHA pada korteks cerebri.

\section{Perbedaan Tumbuh Kembang Bayi dengan ASI, Formula Diperkaya DHA dan Formula Standar}

Jensen $\mathrm{dkk}^{24}$ melaporkan adanya perbedaan berat badan pada usia 17 bulan antara bayi yang mendapat susu formula diperkaya DHA dan susu formula standar, dilaporkan bayi yang mendapat formula yang diperkaya DHA berat badannya lebih besar.

Rendahnya kadar asam lemak tak jenuh ganda rantai panjang di otak bayi prematur yang mendapat susu formula menimbulkan pertanyaan apakah hal tersebut mengganggu fungsi otak. Willats $\mathrm{dkk}^{7}$ menunjukkan bahwa pada usia 10 bulan, kemampuan memecahkan tiga langkah permasalahan lebih baik pada bayi prematur yang mendapat formula yang diperkaya DHA dibandingkan formula standar. 
Penemuan ini penting artinya karena nilai yang lebih tinggi pada kemampuan memecahkan masalah berhubungan dengan kuosien intelegensi (intelligence quotient $=I Q$ ) di kemudian hari. Perbaikan pemecahan masalah disebabkan oleh, pertama akumulasi DHA pada membran sel pada susunan saraf pusat sehingga dapat melancarkan proses informasi. Kedua, penambahan DHA mempercepat maturasi otak khususnya bagian yang bertanggung jawab terhadap timbulnya perhatian terhadap rangsangan. ${ }^{7}$

Birch $\mathrm{dkk}^{8}$ menemukan adanya perbedaan indeks perkembangan mental (mental development index = $M D I)$ dari skala Bayley antara bayi yang mendapat formula yang diperkaya DHA 0,36\% dan formula biasa. Pada bayi kelompok pertama, nilai MDI lebih tinggi secara bermakna dibandingkan kelompok kontrol. Jorgensen $\mathrm{dkk}^{9}$ melaporkan bahwa pada bayi cukup bulan ternyata terdapat perbedaan ketajaman penglihatan saat berusia 4 bulan antara kelompok yang mendapat susu formula standar, formula diperkaya DHA 0,3\% dan ASI. Bayi yang mendapat ASI paling baik ketajaman penglihatannya. SanGiovanni $\mathrm{dkk}^{10}$ menemukan pada bayi prematur terdapat perbedaan ketajaman penglihatan antara bayi yang mendapat susu formula diperkaya DHA dan formula standar. Pada bayi dengan formula diperkaya DHA, ketajaman penglihatan lebih baik.

\section{Rekomendasi Penambahan DHA}

Berdasarkan penelitian akhir-akhir ini tentang DHA pada peran dan fungsinya dalam tumbuh kembang, maka tahun 1993 suatu komisi ahli pada WHO dan $\mathrm{FAO}^{25}$ mengeluarkan suatu rekomendasi bahwa susu formula untuk bayi prematur maupun aterm sebaiknya diperkaya dengan DHA dan asam arakidonat. Sebagai patokan, susu formula sebaiknya memberikan jumlah yang tercantum dalam Tabel 1.

Tahun 1998 Rekomendasi Life Sciences Research
Office (LSRO) untuk FDA seperti dikutip oleh Indarso ${ }^{26}$ menyebutkan bahwa kegunaan penambahan LC-PUFA pada susu formula masih memerlukan evaluasi dalam waktu lima tahun mendatang dan masih belum cukup bukti untuk memberikan rekomendasi bahwa DHA dan AA perlu ditambahkan dalam susu formula.

Tahun 1999, British Nutrition Foundation (BNF) ${ }^{27}$ memberi rekomendasi bahwa bayi cukup bulan maupun prematur telah nyata membutuhkan sumber asam lemak omega 3 dalam makanannya. Dinyatakan juga bahwa bayi prematur membutuhkan LC-PUFA n-3 seperti DHA, namun untuk kebutuhan bayi aterm masih memerlukan penelitian lebih lanjut.

Tahun 1999, Simopoulos $\mathrm{dkk}^{28}$ melaporkan dari Workshop on The Essentiality of and Recommended Dietary Intakes for Omega-6 and omega-3 fatty acids di Bethesda, Maryland, USA, bahwa perbandingan jumlah asam lemak n-6 dan asam lemak n-3 pada makanan bayi baru lahir harus dijaga antara 4:1 hingga $10: 1$.

\section{Kesimpulan}

- DHA merupakan asam lemak tak jenuh ganda rantai panjang yang dibutuhkan dalam pertumbuhan otak khususnya pada masa pacu tumbuh otak.

- ASI mengandung DHA dan kebutuhan bayi akan asam lemak ini dapat dipenuhi dengan pemberian ASI.

- Bayi yang minum susu formula tidak mengandung DHA, tergantung pada sintesis endogen asam lemak tak jenuh rantai panjang. Jumlah dan aktifitas sistim enzim untuk sintesis tersebut masih rendah khususnya pada bayi prematur, sehingga beberapa penelitian mendapatkan kadar DHA pada bayi yang minum susu formula lebih rendah daripada bayi yang minum ASI.

Tabel 1. Patokan jumlah asam linoleat, asam a-linolenat, asam arakidonat dan DHA yang disediakan oleh susu formula.

\begin{tabular}{lcccc}
\hline & $\begin{array}{c}\text { Asam linoleat } \\
(\mathrm{mg} / \mathrm{kg} \mathrm{BB})\end{array}$ & $\begin{array}{c}\text { Asam } \alpha \text {-linolenat } \\
(\mathrm{mg} / \mathrm{kg} \mathrm{BB})\end{array}$ & $\begin{array}{c}\text { Asam arakidonat } \\
(\mathrm{mg} / \mathrm{kg} \mathrm{BB})\end{array}$ & $\begin{array}{c}\text { DHA } \\
(\mathrm{mg} / \mathrm{kg} \mathrm{BB})\end{array}$ \\
Bayi Prematur & 700 & 50 & 60 & 40 \\
Bayi aterm & 600 & 50 & 40 & 20 \\
\hline
\end{tabular}

Dikutip dari $\mathrm{WHO}^{25}$ 
- Beberapa Lembaga Kesehatan dan Nutrisi Dunia telah menganjurkan penambahan DHA pada susu formula dengan memakai patokan jumlah dan perbandingan kandungan DHA dalam ASI.

\section{Daftar Pustaka}

1. Fomon SJ. Infant nutrition. Edisi kedua. Philadelphia: WB Saunders, 1974: h. 152-81.

2. Barness LA. Nutrition for healthy neonates. Dalam: Gracey M, Falker F, penyunting. Nutritional needs and assesment of normal growth. New York: Raven press, 1985:23-43.

3. Koletzko B. Fats for brains. Eur J Clin Nutr 1992; 46:S51-62.

4. Ballabriga A. Lipids in childhood nutrition: Importance of fats in foods composition. Dalam: Ballabriga A, penyunting. Feeding from infants to adolescence. Philadelphia: Lippincott-Raven publ, 1996:h. 63-91.

5. Makrides M, Neumann MA, Byard RW, Simmer K, Gibson RA. Fatty acid composition of brain, retina and erythocytes in breast and formula-fed infants. Am J Clin Nutr 1994; 60:189-94.

6. Makrides M, Neumann MA, Simmer K, Gibson RA. Dietary long-chain polyunsaturated fatty acid do not influence growth of term infants: A randomized clinical trial. Pediatrics 1999; 104: 468-75.

7. Willatts P, Forsyth JS, DiModugno MK, Varma S, Colvin M. Effect of long-chain polyunsaturated fatty acids in infants formula on problem solving at 10 months of age. Lancet 1998; 352:688-91.

8. Birch EE, Garfield S, Hoffman DR, Uauy R, Birch DG. A Randomized controled trial of long-chain polyunsaturated fatty acids and mental development in term infants. Dev Med Child Neurol 2000; 42:174-81.

9. Jorgensen MH, Holmer G, Lund P, Hernell O, Michaelsen KF. Effect of formula suplemented with docosahexaenoic acid and a-linolenic acid on fatty acid status and visual acuity in term infants. J Pediatr Gastrenterol Nutr 1998; 26:412-21.

10. SanGiovanni JP, Parra-Cabrera S, Colditz GA, Berkey CS, Dwyer JT. Meta-analysis of dietary essential fatty acids and long-chain polyunsaturatde fatty acids as they relate to visual resolution acuity in healthy preterm infants. Pediatrics 2000; 105:1292-8.

11. Pusponegoro HD. DHA dan AA, fungsi dan gunanya. Nutrition reviews 2000; 10:8-10.

12. Ho NK. Nutrients in breast milk - Some current topics. Singapure Med J 1999; 40:6-8.

13. Harris WS, Connor WE, Lindsey S. Will dietary omega3 fatty acids change the composition of human milk?
Am J Clin Nutr 1984; 40:780-5.

14. Crawford MA. Essential fatty acid and brain development. Dalam: Horisberger M, Bracco U, eds. Lipids in modern nutrition. New York: Raven press, 1987: h. 6778.

15. Clark KJ, Makrides M, Neumann MA, Gibson RA. Determination of optimal ratio of linoleic acid to alphalinolenic acid in infant formulas. J Pediatr 1992; 120:S151-8.

16. Farquharson J, Cockburn F, Patrick WA, Jamieson EC, Logan RW. Infant cerebral cortex phospholipid fattyacid composition and diet. Lancet 1992; 340:810-3.

17. Mayes PA. Lipid dan makna fisiologis. Dalam: Murray RK, Granner DK, Mayes PA, Rodwell VW, eds. Biokimia Harper edisi 24. Jakarta: EGC, 1996: h. 151-60.

18. Mayes PA. Biosintesis asam lemak. Dalam: Murray RK, Granner DK, Mayes PA, Rodwell VW, eds. Biokimia Harper edisi 24. Jakarta: EGC, 1996:h. 222-9.

19. Guyton AC, Hall JE. Buku ajar fisiologi kedokteran. Edisi 9. Jakarta: EGC, 1996: h. 1077-84.

20. Soemapradja P. Peran asam lemak esensial dalam diit untuk menunjang tumbuh kembang. Dalam: Sularyo TS, Musa DA, Gunardi H. Deteksi dan intervensi dini penyimpangan tumbuh kembang anak dalam usaha optimalisasi kualitas sumber daya manusia. Naskah lengkap PKB IKA XXXVII. Jakarta: Balai Penerbit FKUI 1996:h. 207-13.

21. Connor WE. Importance of n-3 fatty acids in health and disease. Am J Clin Nutr 2000; 7:S171-5.

22. Gibson R. Can we influence brain growth and development of term babies? Disampaikan pada A Lecture tour in Indonesia: Role of omega 3 long chain polyunsaturated fatty acids in neural development, Jakarta, 7-12 Juni 1996.

23. Samsudin. Upaya untuk meningkatkan kualitas susu formula bayi. Disampaikan pada Pertemuan ilmiah Sarihusada, Yogyakarta, 25 Nopember 1995.

24. Jensen CL, Prager TC, Fraley JK, Chen H, Anderson RE, Heird WC. Effect of dietary linoleic/alpha-linolenic acid ratio on growth and visual function of term infants. J Pediatr 1997; 131:200-9.

25. FAO/WHO. Fats and oils in human nutrition: Report of a joint expert consultation. Roma: FAO/WHO, 1993.

26. Indarso F. Peranan LCPUFAs khususnya DHA dan AA pada janin dan bayi. Disampaikan pada Simposium $R a-$ tionale of adding LCPUFAs to infant formula from neurology perspective, Semarang, 2000.

27. British Nutrition Foundation. Unsaturated fatty acids: Nutritional and physiological significance. London: BNF, 1999.

28. Simopoulos AP, Leaf A, Salem N. Workshop on the essentiality of and recommended dietary intakes for omega6 and omega-3 fatty acids. J Am Coll Nutr 1999; 18:4879. 